\title{
Management of Type 2 Diabetes: Current Strategies, Unfocussed Aspects, Challenges, and Alternatives
}

\author{
Swapnil P. Borse ${ }^{a, b}$ Abu Sufiyan Chhipab,c Vipin Sharmad Devendra \\ Pratap Singhe Manish Nivsarkar ${ }^{\mathrm{b}}$
}

${ }^{a}$ AYUSH-Center of Excellence, Center for Complementary and Integrative Health (CCIH), Interdisciplinary School of Health Sciences, Savitribai Phule Pune University (SPPU), Pune, India; ' Department of Pharmacology and Toxicology, B. V. Patel Pharmaceutical Education and Research Development (PERD) Centre, Thaltej, India; ' Institute of Pharmacy, Nirma University, Ahmedabad, India; ${ }^{\mathrm{d} T r a n s l a t i o n a l ~ H e a l t h ~ S c i e n c e ~ a n d ~ T e c h n o l o g y ~ I n s t i t u t e, ~}$ Faridabad, India; 'Sun Pharmaceutical Industries Ltd., Vadodara, India

\section{Highlights}

- Type 2 diabetes is a multifactorial disorder that leads to a disturbed glucose homeostasis.

- Lifestyle management along with pharmacological approaches is crucial to achieve a successful management of diabetes.

- Complex interplays between genetics and environmental factors play important roles in the development of diabetes.

- Combinational therapies employed after failure of monotherapy result in comorbidities.

- Phytoconstituents are better alternatives owing to their multitargeting capability.

\section{Keywords}

Diabetes · Type-2 diabetes mellitus · Insulin resistance $\cdot \beta$-cells - Genetics · Lifestyle modifications · Phytoconstituents

\begin{abstract}
Type 2 diabetes mellitus (T2DM) accounts for $>90 \%$ of the cases of diabetes in adults. Resistance to insulin action is the major cause that leads to chronic hyperglycemia in diabetic patients. T2DM is the consequence of activation of multiple pathways and factors involved in insulin resistance and $\beta$-cell dysfunction. Also, the etiology of T2DM involves the complex interplay between genetics and environmental factors. This interplay can be governed efficiently by lifestyle modifications to achieve better management of diabetes.
\end{abstract}

karger@karger.com www.karger.com/mpp

Karger $\stackrel{\text { ' }}{5}$

GOPEN ACCESS
(C) 2020 The Author(s)

Published by S. Karger AG, Basel

This is an Open Access article licensed under the Creative Commons Attribution-NonCommercial-4.0 International License (CC BY-NC) (http://www.karger.com/Services/OpenAccessLicense), applicable to the online version of the article only. Usage and distribution for commercial purposes requires written permission.
The present review aims at discussing the major factors involved in the development of T2DM that remain unfocussed during the anti-diabetic therapy. The review also focuses on lifestyle modifications that are warranted for the successful management of T2DM. In addition, it attempts to explain flaws in current strategies to combat diabetes. The employability of phytoconstituents as multitargeting molecules and their potential use as effective therapeutic adjuvants to first line hypoglycemic agents to prevent side effects caused by the synthetic drugs are also discussed.

(C) 2020 The Author(s)

Published by S. Karger AG, Basel

Swapnil P. Borse and Abu Sufiyan Chhipa contributed equally; Vipin Sharma and Devendra Pratap Singh contributed equally. 


\section{Introduction}

Insulin resistance and $\beta$-cell dysfunction are the 2 major hallmarks of type 2 diabetes mellitus (T2DM) that appear as the result of disturbed homeostasis [1]. Failure of $\beta$-cells ( $\sim 80 \%$ of their $\beta$-cell function) and insulin resistance in muscles and the liver is a vicious triumvirate responsible for the core physiological defects. However, T2DM is classically viewed as a disorder of insulin deficiency and resistance, and further insights into the pathophysiology of T2DM suggest the role of other key players in insulin deficiency and its functional inability. Pancreatic islets are composed of insulin-releasing $\beta$-cells (48-59\%), glucagonreleasing $\alpha$-cells (33-46\%), somatostatin (SsT)-releasing $\delta$-cells, and F cells that release polypeptides (PPs) in similar proportion [2]. Moreover, paracrine interactions occur in the sequence from $\beta$-cell to $\alpha$-cells followed by $\delta$-cells and $\mathrm{PP}$-cells/F-cells [3]. While the $\beta$-cell interactions are emphasized at present, the interaction of other cells in pancreas is of crucial importance that needs to be explored further to understand their roles in glucose homeostasis [2]. Also, the development of glucose resistance in T2DM is largely influenced by fat cells (accelerated lipolysis), gastrointestinal tract (incretin deficiency/resistance), $\alpha$-cells (hyperglucagonemia), kidneys (increased glucose reabsorption) and brain (insulin resistance), and complex interactions that occur between these factors and T2DM associated genes [4]. Changes in the lifestyle of T2DM patients are crucial along with pharmacological interventions to improve the overall health status of the patient. The present review discusses our current understanding of the pathogenesis of T2DM and attempts to emphasize on generally unfocused aspects of T2DM pathogenesis and treatment that may contribute significantly to treatment approaches and patient-related outcomes.

\section{Understanding the Diabetes Machinery: The Unfocused Aspects}

\section{Amylin Proteins and Pancreatic $\beta$-Cell Function}

$\beta$-Cells are the most extensively studied pancreatic cells for their roles in glucose homeostasis in T2DM. Islet amyloid PP (amylin) is a $\beta$-cell peptide hormone that is secreted along with insulin in the ratio of approximately 100:1. Its secretion is also altered in diabetic patients. Amylin functions as an inhibitor of glucagon secretion and delays gastric emptying thus acting as a satiety agent [5]. Amylin action is executed through an area postrema (glucose-sensitive part of the brain stem) that collectively aims to reduce the demand of total insulin [6]. Besides these functions, amylin also plays roles in the destruction of $\beta$-cell via the formation of amyloid aggregates and fibers [7]. Findings from histopathology have shown the accumulation of extracellular amyloid proteins, hyperphosphorylated tau, ubiquitin, apolipoprotein E, apolipoprotein (a), c-Jun $\mathrm{N}$-terminal kinases (JNK1), and islet-brain 1/JNK1 interacting protein-1 (IB1/JIP-1) as the characteristic feature of pancreatic islets in T2DM individuals, suggesting that amylin in association with endocrine system plays important roles in physiology, pathology, and progression of T2DM [8].

\section{$\alpha$-Cells}

a-cells are known to play crucial roles in the pathophysiology of T2DM. The secretion of glucagon from a-cell is regulated by glucose, hormones, and other substrates that work in unison. Any abnormality in $\alpha$-cells is reflected in altered glucose homeostasis [9]. In T2DM, a relative elevated secretion of glucagon takes place in fasting and postprandial states during normal and increased glucose levels along with altered hypoglycemic response [10]. According to the bi-hormonal hypothesis, T2DM is the consequence of insulin resistance/deficiency with a relative excess glucagon secretion, leading to a rate of hepatic glucose production that is much higher than the rates of glucose utilization. This consequently results in hyperglycemia. The hypothesis is supported by a plethora of clinical and experimental investigations [11, 12]. Reduced suppression of glucagon release under hyperglycemic conditions is a contributing factor to postprandial hyperglycemia [13]. Interestingly, $\alpha$-cells do not show this behavior in the presence of adequate insulin levels, suggesting that impairment in insulin machinery also cause the abnormalities in glucagon release in T2DM [14]. In addition to this, hypoglycemia is remarkably influenced by glucagon secretion in T2DM patients treated with insulin. In such patients, the secretory response of $a$-cells to low-glucose concentrations is compromised, which further aggravates the risks of severe hypoglycemia [15]. The deficiency of glucagon action in response to hypoglycemia is linked with multiple failures in $\alpha$-cell regulation [16]. Even in the situation of islet allotransplantation that helps diabetes patients to remain independent to insulin for a long time, the retarded response of $\alpha$-cell response to hypoglycemia usually remains unaffected, indicating that the procedure does not completely restore the physiological functions of $\alpha$-cells [17]. Collectively, defects in $\alpha$-cell regulation and glucagon secretion lead to defective glucose sensing, loss of $\beta$-cell function, and insulin resistance. 


\section{$\delta$-Cells, SsT, and Pancreatic PP Cells (F-Cells)}

The $\delta$-cells are located in the stomach, intestine, neuroendocrine cells, and pancreas. They secrete SsT in a pulsatile manner in response to fluctuations in glucose levels [18]. SsT regulates the endocrine functions and also plays an important role in the gut-brain axis. The receptors of SsT are present on $\alpha$ - and $\beta$-cells where they act as inhibitory receptors for the secretion of insulin and glucagon. SsT exerts a tonic inhibitory effect on the secretion of insulin and glucagon and facilitates the islet response to cholinergic activation. In addition, SsT is also involved in the suppression of nutrient-induced glucagon secretion [19]. Further, SsT significantly alters the normal glucose homeostasis and feedback loops [20].

F-cells of the pancreas release pancreatic PP after the food intake. It exerts inhibitory postprandial effects on gastric emptying, intestinal motility, exocrine pancreatic secretion, hepatic glucose production, and gallbladder contraction. Functional abilities of PP significantly affect food intake and energy metabolism [21]. When administered through intracerebroventricular route, $\mathrm{PP}$ exerts an orexigenic (appetite stimulating) effect in the brain. On contrary, intraperitoneal administration of PP reduces the food intake and lowers body weight by enhancing energy expenditure [22, 23]. Increased plasma levels of PP are implicated in obesity and diabetes.

\section{Adipose Tissue and Resistin}

Adipose tissue consists of adipocytes, connective tissue matrix, nerve tissue, stromovascular cells, and immune cells. The role of adipose tissue as an endocrine organ is well established [24]. It releases leptin, cytokines, adiponectin, complement components, plasminogen activator inhibitor-1, proteins of the renin-angiotensin system, and resistin. Apart from secreting factors/hormones, adipose tissue also functions in coordination with other hormone systems and the central nervous system. Typically, adipose tissues serve as a store house for fat under normal conditions, while they also release free fatty acids (FFAs) in metabolic disorders. Consistent decline in the function of $\beta$-cell in normal individuals has been shown to be associated with progressive secretion of FFAs and insulin resistance in adipose tissue [25]. Resistin or adipose tissue-specific secretory factor released from adipose tissue is largely implicated in the progression and development of T2DM [24]. It acts as an inhibitory hormone that causes resistance to insulin [26]. Levels of circulating resistin increase in T2DM, resulting in oxidative stress, insulin resistance, and platelet activation [27]. Expression of the resistin gene is also observed in the pancreatic islets, pitu- itary, and hypothalamus [28]. Although resistin is primarily secreted by macrophages in humans [29] where it is involved in the recruitment of immune cells and proinflammatory factors, the involvement of resistin is also seen in hyperglycemia and insulin resistance [30, 31]. Resistin-induced hyperglycemia and obesity are induced through the activation of AMP-protein kinase and decreased expression of gluconeogenic enzymes in the liver. Induction of insulin resistance is also evident in rodents after the administration of recombinant resistin that reverses with the immune neutralization [32].

\section{Genetics}

T2DM is notorious for being "the geneticist's nightmare." Occurring due to the combined contribution of genetic and environmental factors, leading to multiple gene alterations [33]. Multiple mechanisms act either directly or in association with other factors to influence the development and progression of T2DM. These include defects in pancreatic angiogenesis, innervation, and modification of parental imprinting [34]. The pathogenesis of T2DM depends on the intensity of both maternal and paternal insulin resistivity and/or insulin sensitivity [35]. According to one study, the first-degree relatives of T2DM patients live at a higher risk of developing T2DM and have a strong genetic predisposition to $\beta$-cell failure [36]. Moreover, $\beta$-cell dysfunction, autosomal dominance, and heterozygous mutations in $\beta$-cell transcription factors are some of the major causes leading to early onset of T2DM. The identified genes responsible for the early-onset T2DM include insulin promoter factor-1, hepatocyte nuclear factor (HNF)-4a, NeuroD1/BETA2, HNF-1 $\alpha$, and HNF-1 $\beta$ [37]. A hyperglycemic intrauterine environment has also been implicated in T2DM or pre-diabetes in the offspring of women suffering from gestational diabetes [38]. Also, during gestational diabetes, the expression of insulin receptor- $\beta$, PI3K (phosphatidylinositol 3-kinase) with its subunit $\mathrm{p} 85 \alpha$ and GLUT- 4 decreases with a compensatory elevation in the expression of GLUT-1 mRNA in placental tissues [39]. Polymorphism in resistin gene 299 (G>A) and increase in serum resistin is also known to be a contributing factor to increased insulin resistance with a subsequent higher risk of T2DM in offspring. Moreover, offspring carrying AA and combined GA + AA genotypes tend to be at higher risk [40]. On the other hand, diabetes also has the capacity to make genetic alterations leading to associated comorbidities. For instance, alterations in genes involved in vitamin synthesis leads to lowering of levels of riboflavin and glycemia, microalbumineria, and altered levels of uric acid in T2DM individuals and devel- 
opment of insulin resistance due to vitamin D deficiency [41-46]. Importantly, the genes of vitamin D receptor and its binding protein along with CYP1a show polymorphisms in diabetics [42-44].

\section{Gut}

The gut serves as a prominent link between the brain and the enteric nervous system [47]. The secretion of gastrointestinal hormones (incretin, glucagon-like peptide-1 [GLP-1], and glucose-dependent insulinotropic polypeptide [GIP]) increases after food intake. These hormones assist insulin and glucagon in maintaining glucose homeostasis and improve $a$-cell glucose sensing. GLP-1 promotes assimilation of ingested nutrients through glucose-stimulated insulin secretion and evidently improves $\beta$-cell sensitivity to glucose [48]. Moreover, GLP-1 also suppresses glucose-dependent glucagon secretion, retards gastric emptying, and promotes satiety [49]. In the pancreas, $\beta$-cell proliferation and inhibition of apoptosis are promoted by GIP and GLP-1 that ultimately expand pancreatic $\beta$-cell mass. In addition, fat deposition is also facilitated by GIP. In the brain, GIP and GLP-1 are involved in appetite control. GIP also decreases gastric acid secretion, while GLP-1 decreases the duration of gastric emptying. Moreover, the insulinotropic effects of GIP and GLP-1 differ in T2DM patients such that GLP-1 secretion is impaired, while the secretion of GIP remains unaffected [50]. Alterations in incretin functioning and the associated pathways result in increased gastrointestinal permeability in T2DM and form one of the basic underlying mechanisms responsible for diabetic comorbidities in the latter phase $[48,49,51]$.

The gut also releases other hormones which are involved in multiple signaling cascades. These include (but not limited to) ghrelin, galanin, cholecystokinin (CCK or pancreozymin) and leptin [52]. The enteroendocrine cells (I cells of the duodenum and jejunum) and neurons synthesize and release CCK in response to meals and induce pancreatic acinar cells to secrete pancreatic digestive enzymes. CCK also reduces gastric emptying and enhances the digestion process [53]. Vagus stimulation causes trypsin release from pancreas that hydrolyzes CCK to maintain homeostasis through the feedback mechanism. CCK is positively associated with leptin and insulin levels resulting in disrupted glucose homeostasis and diabetic complications in T2DM $[53,54]$.

\section{Gut Microbiota}

Diabetes is considered as a disease of the intestine where gut microbiota plays a crucial role $[55,56]$. The concentration of microflora distally increases along the length of the gastrointestinal tract [57]. The flora of the upper intestine generally accounts for $<10^{5} \mathrm{cfu} / \mathrm{mL}$ of the total microflora content. The concentration of microflora increases in the mid-ileum to $10^{7} \mathrm{cfu} / \mathrm{mL}$ and ultimately populates the colon heavily $[57,58]$. Commonly populating bacteria in humans are (a) Firmicutes (60-80\%): Ruminiococcus, Clostridium, and Lactobacillus; (b) Bacteroidetes (20-30\%): Bacteroides, Prevotella, and Xylanibacter; (c) Actinobacteria (<10\%): Bifidobacterium; (d) Proteobacteria ( $<1 \%)$ : Escherichia and Enterobacteriaceae; and (e) yeast Saccharomyces boulardi [59]. Obesity/ adiposity is undoubtedly a pivotal contributing factor in T2DM. Interestingly, the level of Staphylococcus, Enterobacteriaceae, Faecalibacterium prausnitzii, and E. coli increases during obese conditions, while Bacteroides concentration decreases [60]. Moreover, in T2DM, Firmicutes, Lactobacillus gasseri, Streptococcus mutans, and E. coli are increased, while proteobacteria, butyrate-producing bacteria, Bacteroidetes, Roseburia, Eubacterium halii, and Faecalibacterium prauznitzii are decreased considerably [59]. Changes in gut microbiota/gut-brain microbiota result in insulin resistance and disease/metabolic syndrome [59, 61]. Also, low-grade inflammation is remarkably influenced by obesity in association with alteration of gut-brain-microbiota interactions that render T2DM as an inflammatory disorder [62]. An increased intestinal permeability due to inflammation is evident in obesity and diabetes that may reach to leak gut conditions to facilitate the entry of gut microbes into circulation. This increases circulating LPS and thereby activates inflammasome formation [63]. Moreover, vagal control is significantly compromised in diabetes in association with chronic hyperglycemia, damaged interstitial cells of Cajal and gastroparesis (5-12\% diabetic patients) [64]. Increase in mucosal surface area, intestinal weight, and number of goblet cells per villus leads to disrupted esophagus peristalsis and lower sphincter tone [65]. The overall disturbances in intestinal motor functions lead to stasis and bacterial outgrowth; thus, possibly disturbing the intestinal barrier and affecting permeability to allow the entry of microbes [63-65]. Moreover, circulating LPS are involved in the insulin resistance and diabetes progression toward comorbidities $[63,65,66]$. Gut microbes influence the metabolic and immune networks of the host to cause obesity and diabetes through enhanced nutrient absorption from the diet, cellular uptake of circulating triglycerides, prolonged intestinal transit time, altered bile acid enterohepatic cycle, enhanced de novo lipogenesis, reduced FFA oxidation, altered tissue composition of bi- 
ologically active polyunsaturated fatty acid, chronic lowgrade inflammation triggered by the endotoxin TLR-4 axis, and altered intestinal barrier function [67].

\section{Lifestyle Modifications, Environmental Factors, and Management of T2DM}

The pharmacological approach to treat T2DM can be only partly effective in the long-term management of diabetes. Major modifications in the lifestyle of patients along with the interventions through pharmacological approaches are crucial to ensure an effective management of the disease. These include changes in physical activity, dietary modifications, management of stress or associated factors, and improved sleeping patterns. The next few sections of this review will discuss and explore the potential of these factors in the management of diabetes when followed in parallel with the pharmacological management of the disease.

\section{Physical Activity}

Physical activity is positively associated with controlled glycemic levels among T2DM patients. Moderate but daily physical activity has been found to be an effective way to control the long-term manifestations of diabetes. These include walking, gardening, and performing common household chores. Walking is the most effective physical activity in T2DM, as it allows significant glycemic control with limited physical burden in patients who are already physically weak [68]. Moreover, a much warranted lifestyle alteration in T2DM patients are changes in sedentary patterns. Sedentary behavior leads to considerably low expenditure of energy. An extended sedentary period in T2DM patients is also associated with uncontrolled glycemic levels. A reduced sedentary time, therefore, is crucial in diabetes patients, which can be achieved by increasing the physical work [69]. In addition, regular aerobic exercise is acknowledged to improve $\mathrm{HbAlc} \mathrm{lev-}$ els in patients with diabetes [70]. Aerobic exercise tends to improve health outcomes in patients through multiple mechanisms that include the manifold increase in mitochondrial densities, improved sensitivity to insulin, improved compliance of blood vessels, and lung functions with enhanced cardiac output [71].

\section{Dietary Changes and Medical Nutrition Therapy}

Insulin resistance and subsequent appearance of T2DM are closely linked with high intake of sugars, fried food, and red meat [72]. On the contrary, reduced risk of T2DM development is observed in case of intake of vegetables having high content of antioxidants, fiber, and other nutrients $[73,74]$. The average energy intake of diabetes patients differs with their obesity status. Usually, for a nonobese diabetic patient, an average energy intake of 1,500 2,500 calories per day is recommended, while for obese patients, the average calorie intake is reduced to $800-1,500$ calories per day. Limited intake of refined sugars is highly recommended in T2DM patients. Non-nutritive sweeteners (aspartame, saccharine, etc.) can be the good substitutes for sugar in such patients. Moreover, the restricted intake of food rich in saturated fats and cholesterol and its replacement with food rich in polysaturated fats is also recommended. In addition, changes in eating patterns, such as dividing meals into small fractions over the day rather than taking 1 or 2 large meals can prevent vigorous postprandial peaks in blood glucose levels [75]. Strict adherence to controlled diet with sufficient physical activity is largely associated with lower incidence of diabetes [76]. Incorporation of Paleolithic diet (a diet rich in lean meat, fish, fruits, and vegetables) in the daily routine of diabetic patients results in marked improvement in glucose handling [77]. The employment of nutritional therapy in the management of diabetes is also widely suggested. Nutritional therapy is an approach to treat a disease through the modifications in food and nutrition intake. The application of evidence-based nutrition care therapy in diseased patients by a qualified and registered dietician is termed as medical nutrition therapy [78]. Reduced reliance on oral hypoglycemic therapy is evident in diabetes patients receiving nutritional therapy [79]. Also, considerable improvements in clinical outcomes are observed in diabetes patients receiving intensive nutritional education by registered dietician in comparison to patients receiving basic nutrition information (BE) [80]. Taken together, simple but profound changes in dietary pattern in diabetic patients is a potential approach to curb the long-term implications of diabetes. Moreover, successful application of nutritional therapy in individuals with diabetic conditions can be a lucrative approach to achieve a better management of diabetes with improved health outcomes.

\section{Stress}

Increased levels of stress are associated with poor treatment adherence and glycemic control in T2DM patients [81]. In a longitudinal study, moderate/high levels of stress were found to be accountable for multifold increase in the incidences of diabetes [82]. Moreover, consistent exposure to stressors, compromised mental health, and psychological stress are highly implicated in increasing 
risk of T2DM development [83]. Allostatic load (wear and tear in the body occurring as a result of chronic exposure to psychological stress) is assumed to be the major factor responsible for this increased risk of T2DM in such individuals [84]. In addition, consistent stress is also implicated in worsening of clinical outcomes in T2DM patients. Chronic stress is associated with dysregulated glucose metabolism and neuroendocrine function accompanied with low-grade inflammation. A majority of factors that are implicated in T2DM are largely influenced by psychological stress including the release of glucose (and lipids) in circulation, expression of inflammatory cytokines, and elevated blood pressure [85]. In one study, in type 2 diabetes patients when exposed to acute stress during the postprandial period, considerable increases in blood glucose levels were observed [86]. Apparently, treatment strategies, including stress management interventions, are a promising approach in effectively preventing or controlling the incidence of type 2 diabetes.

\section{Sleep Patterns and Chronopharmacology}

Although physical activity and maintained dietary pattern result in considerable improvements in the management of T2DM, they cannot be envisioned as the sole contributors to the worsening of diabetes incidences. Sleep is another modifiable lifestyle behavior that has proven roles in influencing metabolic health and energy status. Optimization of sleeping patterns is crucial in diabetes control [87]. A population-based study suggests that short sleep $(<5 \mathrm{~h})$ or insomnia is associated with increased risk of T2DM [88]. In similar studies, poor sleep was associated with higher $\mathrm{HbAlc}$ levels $(>7 \%)$ and insulin resistance in T2DM patients [88]. Disturbed circadian rhythms and sleep-wake patterns also result in significant effect on onset, development, and management of diabetes [89]. Shift workers tend to remain much prone to metabolic disorders due to consistent sleep loss and disrupted circadian rhythm [90]. In addition, developed propensity of napping as a consequence of poor or insufficient nocturnal sleep is also associated with high risk of T2DM [91]. In one study, experimental manipulation of sleep and circadian pattern resulted in significant reduction in insulin response to standardized meal which could be recovered with restored sleeping patterns [92]. Changes in hormones that regulate appetite (leptin and ghrelin) are observed to be associated with short sleep causing an increased urge for carbohydrate-rich food and increased calorie intake $[89,93]$. Moreover, lack of sleep also results in oxidative stress and release of orexin or hypocretin, a neuropeptide that regulates sleep and appetite and causes the stimulation of sympathetic nervous system and increased release of cortisol with simultaneous decrease in growth hormone secretion, all leading to considerable hyperglycemia $[89,94]$.

Pharmacokinetics and pharmacodynamics (PK-PD) are markedly influenced by daily rhythms in physiology. This phenomenon is termed chronopharmacology [95]. Indeed, the pathogenesis of diabetes largely depends on hormonal and body homeostasis. Chronopharmacology should be considered as part of treatment strategies for diabetes. The failing $\beta$-cells in T2DM do not lose all their capability to respond to glucose. Insulin secretion in response to stimulation through amino acids or other hormones such as glucagon-like peptide 1 (GLP-1), remains preserved [96]. The levels of leptin (satiety hormone) in blood generally remain higher between midnight and early morning, conceivably to suppress appetite during the night [97]. Moreover, the levels of ghrelin increase with increase in the duration of sleep [93]. In addition, the time dependency in GLUT4-mediated glucose uptake is also a function of circadian variation [98]. Furthermore, meal timings can modify the diurnal rhythm of blood leptin levels [99]. Both ghrelin and leptin work with other hormones and HPA axis through feedback loops to indirectly affect the psychophysiological satisfaction in diabetic patients [100]. Chronopharmacology, therefore, may considerably affect diabetic pathophysiology and PK-PD of administered drugs.

\section{Interplay of Genetics, Gut Microbiota, Lifestyle, and Environmental Factors}

Multiple epidemiological investigations have suggested that the effects of multiple T2DM-associated loci can be attenuated by improving lifestyle, dietary patterns, and other associated environmental factors. For instance, the Ala12 variant of PPAR $\gamma$ is associated with improved insulin sensitivity. Apparently, the Ala12 carriers are more responsive to unsaturated fat and less responsive to saturated fat. On contrary, the Pro12 variant carriers of PPAR $\gamma$ are more responsive to the deleterious effects of saturated fat and altered glucose homeostasis. Seemingly, unsaturated fat interacts with PPAR $\gamma$ Ala12 variant and upregulates the activity of latter [101]. Potential gene-environment $(G \times E)$ interactions also occur between TCF7L2 risk-variant (rs7903146) and lifestyle modifications (physical activity, MNT, and dietary changes). Decreased insulin resistance and reduced risk in TCF7L2 risk-variant carriers is significantly affected by lifestyle modifications 
$[102,103]$. A common SNP in fat mass and obesity associated gene (FTO rs9939609) is associated with increased risk of T2DM. Increased physical activity reduces the FTO rs9939609-induced obesity and associated risk of T2DM [104]. SNP in glucokinase regulatory protein gene results in an insulin-raising allele, GCKRrs780094. Its interaction with the whole grain (increased whole grain intake) results in reduced fasting insulin in the carriers [105]. The potassium voltage-gated channel subfamily $\mathrm{Q}$ member 1 (KCNQ1) is a susceptible gene in T2DM. Mutations in KCNQ1 are associated with decreased insulin secretion. Reduced expression of noncoding RNA Kcnqlotl in Kcnq1 genetic region leads to increase in cyclin-dependent kinase inhibitor $1 \mathrm{C}(\mathrm{Cdkn} 1 \mathrm{c})$ expression, resulting in reduced pancreatic $\beta$-cell mass and insulin release. The CCAAT sequence in the promoter region of Cdkn $1 \mathrm{c}$ gene serves as the binding site for transcription factor C/EBP that increases the further expression of Cdkn1c. Evidently, the expression of $\mathrm{C} / \mathrm{EBP} \beta$ results in endoplasmic reticulum stress to cause dysfunctions in $\beta$-cells. The accumulation of $\mathrm{C} / \mathrm{EBP} \beta$ in pancreatic $\beta$-cells increases in the presence of high fat diet, thereby potentiating the $\beta$-cells dysfunction in the vulnerable population [106]. Collectively, the emerging investigations to explore the interactions between gene and environmental factors suggest a high influence of dietary patterns, physical exercise, and other lifestyle interventions on the expression of genes that are peculiar to the development of T2DM.

Apart from gene expression, environmental factors also tend to exert a potential impact on gut microbiota. The gut environment is affected by a number of factors including the diet, $\mathrm{pH}$, and nutrient absorption. While the presence of Firmicutes and Proteobacteria increases under the influence of carbohydrates and simple sugarrich diet, saturated fats, and animal protein-rich diet encourages the proliferation of Bacteroidetes and Actinobacteria [107]. Moreover, a high -at diet is also accountable for significant alterations in intestinal flora, including the Bifidobacterium and Bacteroides (increased Gramnegative/Gram-positive bacteria ratio). This allowed and increased secretion of LPS, fat content, body weight, and inflammatory reactions associated with T2DM [108]. Reduction in butyrate is largely responsible for the loss of tight intestinal barrier. An intestinal $\mathrm{pH}$ of 5.5 favors the proliferation of butyrate-producing Phytophthora which starts to diminish with a $\mathrm{pH}$ value of 6.5 [109]. In addition, the hypoglycemic agents utilized for the antidiabetic therapy also pose a remarkable influence on the gut microbiota. Metformin and acarbose are known to increase the proliferation of lactobacilli, Akkermansia, and several other bacteria that are acknowledged to exert beneficial effects in diabetes [110].

Gut microbiota composition also affects the regulation of expression of different genes in T2DM. Although reports are limited in terms of potential interactions between gut microbes and T2DM associated gene variants, existing reports on the influence of gut microbes in the expression genes that are crucial in T2DM are highly suggestive of a complex gene-microbes interplay in the etiology of T2DM. Also, microbiome plays a crucial role in the epigenetic regulation of genes by the modification of DNA methylation [111]. F. prausnitzii, a short-chain fatty acid-producing bacteria was found crucial in epigenetic regulation of FFA receptor gene in patients of T2DM. A significant reduced presence of $F$. prausnitzii was evident in such patients. As a result, a considerably low methylation in the promoter region of FFA receptor gene is observed in these individuals [112]. Increased release of pro-inflammatory cytokines is a key event in T2DM. Microbes are largely known to be associated with increased release of inflammatory cytokines by producing the products such as LPS that promote low-grade inflammation and endotoxemia. On contrary, several microbes are known to induce the expression of anti-inflammatory cytokines, including the IL-10 and IL-22, that have proven roles in improving the insulin sensitivity Roseburia intestinalis, Bacteroides fragilis, Akkermansia muciniphila, Lactobacillus plantarum, and Lactobacillus casei [113]. Two other beneficial microbes - Bacteroides vulgatus and Bacteroides dorei - are observed to increase the expression of tight junction genes in T2DM to compensate with the compromised gut permeability (leaky gut) [114]. A major contribution of probiotics is observed in the case of glucose metabolism and homeostasis. For instance, $L$. gasseri BNR17 is known to increase the expression of GLUT-4 transporter gene [115]. Another gut microbe, $L$. casei is witnessed to increase the expression of multiple T2DM-related genes, including $\mathrm{ClC1}-7$, GlyRa1, SLC26A3, SLC26A6, GABAAa1, Bestrophin-3, and CFTR, thus resulting in a significant reduction in hyperglycemia [116]. It appears to be of vital importance to consider the potential interplay between various T2DMrelated genes and these microbes. Undoubtedly, the absence of these microbes among the gut microbiota can be largely responsible for the altered regulation of different genes in T2DM patients. Also, exploring the interactions between different T2DM-associated gene variants and gut microbiota is warranted to further understand the complex interactions between environmental factors, gut microbiota, and genetics in the development of T2DM. 
Table 1. Multiple targets of different phytoconstituents in the management of T2DM and their possible outcomes [133-140]

\begin{tabular}{|c|c|c|}
\hline Phytoconstituents & Mode of action/targets & Outcomes \\
\hline Curcumin & $\begin{array}{l}\downarrow \text { TNF- } \alpha, \downarrow \text { NFkB activation, } \downarrow \text { lipid peroxidation, } \downarrow \text { lysozyme } \\
\text { enzyme activity, and } \uparrow \text { PPAR- } \gamma \text { activation }\end{array}$ & $\begin{array}{l}\text { Increased insulin sensitivity, decreased glucose intolerance, and } \\
\text { hypoglycemia [133] }\end{array}$ \\
\hline Rutin & $\begin{array}{l}\downarrow \text { G6Pase and glycogen phosphorylase activity, } \uparrow \text { hepatic } \\
\text { hexokinase activity, and } \uparrow \text { PPAR } \gamma \text { activation }\end{array}$ & $\begin{array}{l}\downarrow \text { Hepatic glucose production, } \uparrow \text { glucose tolerance, and } \\
\text { improved insulin sensitivity [134] }\end{array}$ \\
\hline Resveratrol & $\begin{array}{l}\text { SIRT } 1 \text { activation, } \downarrow \text { oxidative stress, and } \uparrow \text { GLUT4 translocation } \\
\text { through AMPK/Akt/iNOS signaling pathway }\end{array}$ & $\begin{array}{l}\text { Improved insulin signaling, } \uparrow \text { glucose-mediated insulin } \\
\text { secretion, and } \downarrow \text { loss of } \beta \text { cells [135] }\end{array}$ \\
\hline Quercetin & $\begin{array}{l}\uparrow \text { GLUT4 translocation through AMPK signaling, } \downarrow \text { G6Pase, and } \\
\text { ERK1/2 activation }\end{array}$ & $\begin{array}{l}\uparrow \text { Glucose uptake, } \downarrow \text { hepatic glucose production, glucose- } \\
\text { induced insulin secretion, and improves } \beta \text {-cell function }[135 \text {, } \\
136]\end{array}$ \\
\hline Genistein & $\uparrow$ Hepatic hexokinase activity, and $\downarrow$ cytosolic PEPCK & $\begin{array}{l}\text { Improved lipid and glucose metabolism and reduced fasting } \\
\text { glucose [137] }\end{array}$ \\
\hline Naringenin & $\uparrow$ Expression of GLUT4 and PPAR $\gamma$ & $\begin{array}{l}\uparrow \text { Glucose uptake, decreased glucose intolerance, and reduced } \\
\text { blood glucose levels [139] }\end{array}$ \\
\hline $\begin{array}{l}\text { Vitamins A, D, } \\
\text { and E }\end{array}$ & $\begin{array}{l}\uparrow \operatorname{PPAR} \beta / \delta \text { expression, } \uparrow \text { RAR expression, } \uparrow \text { DNA tail length of } \\
\text { liver and pancreas, and } \downarrow \text { G6Pase, } \downarrow \beta \text {-cell apoptosis }\end{array}$ & $\begin{array}{l}\text { Decreased glucose intolerance, } \uparrow \beta \text {-cell mass, } \downarrow \text { hepatic glucose, } \\
\text { and } \downarrow \text { hyperglycemia [135] }\end{array}$ \\
\hline Fisetin & $\downarrow$ G6Pase and $\downarrow$ cytosolic PEPCK & $\begin{array}{l}\downarrow \text { Hepatic glucose and improved lipid and glucose metabolism } \\
{[140]}\end{array}$ \\
\hline
\end{tabular}

T2DM, type 2 diabetes mellitus; G6Pase, glucose-6-phosphatase; PEPCK, phosphoenolpyruvate carboxykinase.

\section{Current Approaches for Diabetes Management: What Are We Missing?}

The guidelines for the pharmacological management of diabetes provided by American Diabetes Association suggest that metformin be prescribed as the initial intervention to T2DM patients. However, the same guideline also indicates that vitamin $\mathrm{B}_{12}$ deficiency is a prominent side effect observed in metformin consumers and a periodic vitamin $B_{12}$ measurement is required in such patients $[117,118]$. Furthermore, metformin is also notorious for causing lactic acidosis, especially in patients with kidney disease, liver injury, or other CVS complications that create a low level of oxygen in circulation [119]. For T2DM patients with cardiovascular or CKDs, the guidelines recommend adding sodium-glucose cotransporter 2 (SGTL2) inhibitors and/or glucagon-like peptide 1 receptor agonists along with hypoglycemic agents [118]. The employability of SGTL2 inhibitors with almost all classes of hypoglycemic agents makes them ideal candidates to be combined when dual and triple combination therapies are warranted [120]. In an ideal scenario, a drug used in combination should be able to reverse the pathology with an improved overall health status of the patient and ensure that no new complications arise due to the existing management strategies. In case of T2DM, drug combination should not only be able to just merely reduce the glycosylated hemoglobin levels (HbA1C) but also an improved overall metabolic condition of the patient is expected through suchinterventions [120]. The combination of SGTL2 inhibitors with metformin may have proved beneficial in curbing hyperglycemia that cannot be controlled by metformin alone [120], but the adverse effects associated with the SGTL2 inhibitors still remain unresolved. Genital infections caused by SGTL2 inhibitors due to high glycosuria still remain an unfocussed aspect while prescribing such combinations. In addition, during the event of excessive osmotic diuresis caused by SGTL2 inhibitors, a low extracellular fluid volume and subsequent hypotension is another complication that may arise [121]. Multiple reports have also raised concerns regarding the use of SGTL2 inhibitors in diabetes due to their substantial involvement in causing diabetic ketoacidosis [122]. Two separate reports published in 2015 claimed 
that canagliflozin, an SGTL2 inhibitor is implicated in pancreatitis in T2DM patients [123, 124]. GLP-1 agonists are also a preferred class of adjuvant hypoglycemic agents that are combined with first-line hypoglycemics [125]. Apart from gastrointestinal disorders (nausea, vomiting, and constipation), infections and acute renal injury, a major raising concern regarding the use of GLP-1 agonists is their association with pancreatitis $[125,126]$. Cases of acute pancreatitis are reported with the use of liraglutide and exenatide [127, 128]. More importantly, recent reports also raise concerns regarding the long-term reliance on incretin-based therapies due to frequently reported cases of their association with pancreatitis and pancreatic cancer [129]. Studies based on FDA Adverse Events Reporting System demonstrated that incretinbased therapies are associated with the increased incidences of pancreatic and thyroid cancer $[130,131]$. Exenatide use is also positively associated with the incidences of bone fractures [132].

\section{Alternatives: Phytoconstituents}

Failure of monotherapy in diabetes is simply managed by the dual or triple drug combination therapies that involve the addition of supportive hypoglycemic agents with the first-line drugs. However, adding the supportive or second-line drugs in combination seldom includes the assessment of risk factors associated with these new additions. The sole aim of these therapies remains to be a controlled glycemic condition. Unfortunately, in the pursuit of maintaining normal blood glucose levels, the occurrence of new complications is largely taken for granted. Monotherapies supplemented with herbal extracts or phytoconstituents have showed appreciable improvements in the blood glucose levels in diabetic patients. Chemical constituents from plants have also proved to be promising alternatives. Table 1 represents the known effects of different phytoconstituents in diabetes exerted through multiple targets. As a result, unlike in the case of conventional single target therapy where chances of treatment failures are high, therapy failures with multi-targeting approach are rare.

\section{Conclusions}

Diabetes is a metabolic disorder that is influenced by a variety of factors. Recent insights into the pathogenesis of diabetes have unraveled newer pathways and factors that contribute substantially in disease development and progression. Insulin resistance and $\beta$-cell dysfunction are the 2 major events that are largely responsible for the onset of diabetes. A major objective of this review is to focus on the unfocused aspects of diabetes to develop better strategies for diabetes treatment. In this review, we have discussed the factors that have played crucial roles in the etiology of T2DM but have not received adequate attention. We have also discussed the efficiency of existing approaches in the treatment of T2DM. Lifestyle modifications that favor the improvement of management of diabetes and their complex interplays with genetics and gut environment is a crucial factor that warrants further research in the development of more efficient and individualized therapy approaches for disease treatment. The use of multidrug combination therapy in diabetes may have improved health outcomes in T2DM patients and also result in additional complications that need serious consideration. Moreover, more attention is required toward the developing comorbidities during diabetes. The diabetic milieu accelerates the formation of advanced glycation end products that may encourage the development of diabetic complications and even cancer in diabetic patients. Multiple pathways are involved in diabetes that can contribute to the manifestation of comorbidities that are largely neglected during disease treatment.

Multitargeting is a promising approach for the treatment of T2DM as it includes multiple pathways. The failure of single target approaches is the major challenge faced in T2DM treatment. Phytoconstituents are promising as they interact with multiple pathways simultaneously. However, the reluctance to rely on phytoconstituents as the main therapy still remains as a limiting factor for such drugs to serve as mainstream interventions.

\section{Acknowledgement}

The authors are thankful to B. V. Patel Pharmaceutical Education and Research Development (PERD) Center, Ahmedabad, and AYUSH - Center of Excellence, Center for Complimentary and Integrative Health (CCIH), Interdisciplinary School of Health Sciences, Savitribai Phule Pune University, Pune, for providing facilities for the successful completion of the work. The authors are also thankful to those colleagues whose work could not be cited directly owing to space constraints.

\section{Conflict of Interest Statement}

All authors have read the journal's policy on disclosure of potential conflicts of interest and have none to declare. 


\section{References}

1 Ahmad LA, Crandall JP. Type 2 diabetes prevention: a review. Clin Diabetes. 2010;28(2): 53-9.

2 Quesada I, Tudurí E, Ripoll C, Nadal Á. Physiology of the pancreatic $\alpha$-cell and glucagon secretion: role in glucose homeostasis and diabetes. J Endocrinol. 2008;199(1):5-19.

3 Brissova M, Fowler MJ, Nicholson WE, Chu A, Hirshberg B, Harlan DM, et al. Assessment of human pancreatic islet architecture and composition by laser scanning confocal microscopy. J Histochem Cytochem. 2005; 53(9):1087-97.

4 DeFronzo RA. From the triumvirate to the ominous octet: a new paradigm for the treatment of type 2 diabetes mellitus. Diabetes. 2009;58(4):773-95.

5 Schmitz O, Brock B, Rungby J. Amylin agonists: a novel approach in the treatment of diabetes. Diabetes. 2004;53(Suppl 3):S233-8.

6 Pittner RA, Albrandt K, Beaumont K, Gaeta LS, Koda JE, Moore CX, et al. Molecular physiology of amylin. J Cell Biochem. 1994 55(S1994A):19-28.

7 Höppener JW, Oosterwijk C, van Hulst KL, Verbeek JS, Capel PJ, de Koning EJ, et al. Molecular physiology of the islet amyloid polypeptide (IAPP)/amylin gene in man, rat, and transgenic mice. J Cell Biochem. 1994 55(S1994A):39-53.

8 Miklossy J, Qing H, Radenovic A, Kis A, Vileno $B$, Làszló $F$, et al. Beta amyloid and hyperphosphorylated tau deposits in the pancreas in type 2 diabetes. Neurobiol Aging. 2010 31(9):1503-15.

9 Jacobson DA, Wicksteed BL, Philipson LH. The a-cell conundrum: ATP-sensitive $\mathrm{K}+$ channels and glucose sensing. Diabetes. 2009 58(2):304-6.

10 Reaven GM, Chen YD, Golay A, Swislocki AL, Jaspan JB. Documentation of hyperglucagonemia throughout the day in nonobese and obese patients with noninsulin-dependent diabetes mellitus. J Clin Endocrinol Metab. 1987 Jan;64(1):106-10.

11 Consoli A, Nurjhan N, Capani F, Gerich J. Predominant role of gluconeogenesis in increased hepatic glucose production in NID DM. Diabetes. 1989;38(5):550-7.

12 Dunning BE, Gerich JE. The role of alpha-cell dysregulation in fasting and postprandial hyperglycemia in type 2 diabetes and therapeutic implications. Endocr Rev. 2007;28(3):253-83.

13 Shah P, Vella A, Basu A, Basu R, Schwenk WF, Rizza RA. Lack of suppression of glucagon contributes to postprandial hyperglycemia in subjects with type 2 diabetes mellitus. J Clin Endocrinol Metab. 2000 Nov;85(11):4053-9.

14 Shah P, Basu A, Basu R, Rizza R. Impact of lack of suppression of glucagon on glucose tolerance in humans. Am J Physiol. 1999 Aug; 277(2 Pt 1):E283-90

15 Cryer P. Hypoglycaemia: the limiting factor in the glycaemic management of type I and type II diabetes. Diabetologia. 2002;45(7):937-48.
16 Zhou H, Zhang T, Oseid E, Harmon J, Tonooka N, Robertson RP. Reversal of defective glucagon responses to hypoglycemia in insulin-dependent autoimmune diabetic BB rats. Endocrinology. 2007;148(6):2863-9.

17 Paty BW, Ryan EA, Shapiro AM, Lakey JR, Robertson RP. Intrahepatic islet transplantation in type 1 diabetic patients does not restore hypoglycemic hormonal counterregulation or symptom recognition after insulin independence. Diabetes. 2002;51(12):3428-34.

18 Van Der Meulen T, Donaldson CJ, Cáceres E, Hunter AE, Cowing-Zitron C, Pound LD, et al. Urocortin 3 mediates somatostatin-dependent negative feedback control of insulin secretion. Nat Med. 2015;21(7):769-76.

19 Hauge-Evans AC, King AJ, Carmignac D, Richardson CC, Robinson IC, Low MJ, et al. Somatostatin secreted by islet delta-cells fulfills multiple roles as a paracrine regulator of islet function. Diabetes. 2009;58(2):403-11.

20 Orci L, Baetens D, Rufener C, Amherdt M, Ravazzola M, Studer P, et al. Hypertrophy and hyperplasia of somatostatin-containing Dcells in diabetes. Proc Natl Acad Sci U S A. 1976;73(4):1338-42.

21 Khandekar N, Berning BA, Sainsbury A, Lin $S$. The role of pancreatic polypeptide in the regulation of energy homeostasis. Mol Cell Endocrinol. 2015;418(Pt 1):33-41.

22 Asakawa A, Inui A, Ueno N, Fujimiya M, Fujino MA, Kasuga M. Mouse pancreatic polypeptide modulates food intake, while not influencing anxiety in mice. Peptides. 1999; 20(12):1445-8.

23 Ueno N, Inui A, Iwamoto M, Kaga T, Asakawa A, Okita $\mathrm{M}$, et al. Decreased food intake and body weight in pancreatic polypeptideoverexpressing mice. Gastroenterology. 1999; 117(6):1427-32.

24 Booth A, Magnuson A, Fouts J, Foster MT. Adipose tissue: an endocrine organ playing a role in metabolic regulation. Horm Mol Biol Clin Investig. 2016;26(1):25-42.

25 Gastaldelli A, Gaggini M, DeFronzo RA. Role of adipose tissue insulin resistance in the natural history of T2DM: results from the San Antonio metabolism study. Diabetes. 2017: db161167.

26 Berger A. Resistin: a new hormone that links obesity with type 2 diabetes. BMJ. 2001; 322(7280):193-3.

27 Santilli F, Liani R, Di Fulvio P, Formoso G, Simeone $\mathrm{P}$, Tripaldi $\mathrm{R}$, et al. Increased circulating resistin is associated with insulin resistance, oxidative stress and platelet activation in type 2 diabetes mellitus. Thromb Haemost. 2016;116(6):1089-99.

28 Lazar M. Resistin- and obesity-associated metabolic diseases. Horm Metab Res. 2007; 39(10):710-6

29 Schwartz DR, Lazar MA. Human resistin: found in translation from mouse to man. Trends Endocrinol Metab. 2011;22(7):25965.
30 Banerjee RR, Rangwala SM, Shapiro JS, Rich AS, Rhoades B, Qi Y, et al. Regulation of fasted blood glucose by resistin. Science. 2004 303(5661):1195-8.

31 Barnes KM, Miner JL. Role of resistin in insulin sensitivity in rodents and humans. Curr Protein Pept Sci. 2009 Feb;10(1):96-107.

32 Steppan CM, Bailey ST, Bhat S, Brown EJ, Banerjee RR, Wright CM, et al. The hormone resistin links obesity to diabetes. Nature. 2001;409(6818):307-12.

33 Gloyn AL. The search for type 2 diabetes genes. Ageing Res Rev. 2003 Apr;2(2):11127.

34 Simeoni U, Barker DJ. Offspring of diabetic pregnancy: long-term outcomes. Semin Fetal Neonatal Med. 2009 Apr;14(2):119-24.

35 Warram JH, Krolewski AS, Gottlieb MS Kahn CR. Differences in risk of insulin-dependent diabetes in offspring of diabetic mothers and diabetic fathers. N Engl J Med. 1984;311(3):149-52.

36 Cnop M, Vidal J, Hull RL, Utzschneider KM, Carr DB, Schraw T, et al. Progressive loss of beta-cell function leads to worsening glucose tolerance in first-degree relatives of subjects with type 2 diabetes. Diabetes Care. 2007; 30(3):677-82.

37 Frayling TM, Evans JC, Bulman MP, Pearson E, Allen L, Owen K, et al. Beta-cell genes and diabetes: molecular and clinical characterization of mutations in transcription factors. Diabetes. 2001;50(Suppl 1):S94.

38 Pettitt DJ, Bennett PH, Knowler WC, Baird HR, Aleck KA. Gestational diabetes mellitus and impaired glucose tolerance during pregnancy: long-term effects on obesity and glucose tolerance in the offspring. Diabetes. 1985;34(Suppl 2):119-22.

39 Colomiere M, Permezel M, Riley C, Desoye G Lappas M. Defective insulin signaling in placenta from pregnancies complicated by gestational diabetes mellitus. Eur J Endocrinol. 2009 Apr;160(4):567-78.

40 Fawzy F, Khalil O, Salem H, Fawzy M. Resistin gene polymorphism in offspring of patients with type 2 diabetes mellitus. 18th European Congress of Endocrinology: BioScientifica; 2016.

41 Pittas AG, Lau J, Hu FB, Dawson-Hughes B. The role of vitamin $\mathrm{D}$ and calcium in type 2 diabetes. A systematic review and meta-analysis. J Clin Endocrinol Metab. 2007 Jun;92(6): 2017-29.

42 Palomer X, González-Clemente JM, BlancoVaca F, Mauricio D. Role of vitamin D in the pathogenesis of type 2 diabetes mellitus. Diabetes Obes Metab. 2008;10(3):185-97.

43 Sung CC, Liao MT, Lu KC, Wu CC. Role of vitamin $\mathrm{D}$ in insulin resistance. J Biomed Biotechnol. 2012;2012:634195.

44 Cangoz S, Chang YY, Chempakaseril SJ, Guduru RC, Huynh LM, John JS, et al. Vitamin $\mathrm{D}$ and type 2 diabetes mellitus. J Clin Pharm Ther. 2013;38(2):81-4 
45 Tilg H, Moschen AR. Microbiota and diabetes: an evolving relationship. Gut. 2014;63(9): 1513-21.

46 Sipahi S, Acikgoz SB, Genc AB, Yildirim M, Solak Y, Tamer A. The association of vitamin $\mathrm{D}$ status and vitamin $\mathrm{D}$ replacement therapy with glycemic control, serum uric acid levels, and microalbuminuria in patients with type 2 diabetes and chronic kidney disease. Med Princ Pract. 2017;26(2):146-51.

47 Mayer EA. Gut feelings: the emerging biology of gut-brain communication. Nat Rev Neurosci. 2011 Jul 13;12(8):453-66.

48 Dunning BE, Foley JE, Ahrén B. Alpha cell function in health and disease: influence of glucagon-like peptide-1. Diabetologia. 2005; 48(9):1700-13.

49 Freeman JS. Role of the incretin pathway in the pathogenesis of type 2 diabetes mellitus. Cleve Clin J Med. 2009;76(Suppl 5): S12-9.

50 Seino Y, Fukushima M, Yabe D. GIP and GLP-1, the two incretin hormones: similarities and differences. J Diabetes Investig. 2010 Apr 22;1(1-2):8-23.

51 Cernea S. The role of incretin therapy at different stages of diabetes. Rev Diabet Stud. 2011;8(3):323-38.

52 Milewicz A, Mikulski E, Bidzińska B. Plasma insulin, cholecystokinin, galanin, neuropeptide $\mathrm{Y}$ and leptin levels in obese women with and without type 2 diabetes mellitus. Int $J$ Obes Relat Metab Disord. 2000;24(Suppl 2): S152.

53 Liddle RA. Regulation of cholecystokinin secretion by intraluminal releasing factors. Am J Physiol. 1995;269(3 Pt 1):G319-27.

54 Chaudhri O, Small C, Bloom S. Gastrointestinal hormones regulating appetite. Philos Trans R Soc Lond B Biol Sci. 2006 Jul 29; 361(1471):1187-209.

55 Flint HJ, Scott KP, Louis P, Duncan SH. The role of the gut microbiota in nutrition and health. Nat Rev Gastroenterol Hepatol. 2012; 9(10):577-89.

56 Sanyal D. Diabetes is predominantly an intestinal disease. Indian J Endocrinol Metab. 2013;17(Suppl 1):S64.

57 Gorbach SL, Goldin BR. Nutrition and the gastrointestinal microflora. Nutr Rev. 1992; 50(12):378-81.

58 Putignani L. Human gut microbiota: onset and shaping through life stages and perturbations. Frontiers E-books; 2013.

59 Muñoz-Garach A, Diaz-Perdigones C, Tinahones FJ. Gut microbiota and type 2 diabetes mellitus. Endocrinología y Nutrición English Edition; 2016

60 Nadal I, Santacruz A, Marcos A, Warnberg J, Garagorri JM, Moreno LA, et al. Erratum: shifts in clostridia, bacteroides and immunoglobulin-coating fecal bacteria associated with weight loss in obese adolescents. Int $\mathrm{J}$ Obes. 2012;36(10):1370.

61 Sommer F, Bäckhed F. The gut microbiota: masters of host development and physiology. Nat Rev Microbiol. 2013;11(4):227-38.
62 Esser N, Legrand-Poels S, Piette J, Scheen AJ, Paquot N. Inflammation as a link between obesity, metabolic syndrome and type 2 diabetes. Diabetes Res Clin Pract. 2014;105(2): 141-50.

63 De Kort S, Keszthelyi D, Masclee AA. Leaky gut and diabetes mellitus: what is the link? Obes Rev. 2011;12(6):449-58.

64 Boland BS, Edelman SV, Wolosin JD. Gastrointestinal complications of diabetes. Endocrinol Metab Clin North Am. 2013;42(4):809-32.

65 Rayner CK, Horowitz M. Gastrointestinal motility and glycemic control in diabetes: the chicken and the egg revisited? J Clin Invest. 2006 Feb 1;116(2):299-302.

66 Donath MY, Dalmas É, Sauter NS, BöniSchnetzler M. Inflammation in obesity and diabetes: islet dysfunction and therapeutic opportunity. Cell Metab. 2013;17(6):860-72.

67 Musso G, Gambino R, Cassader M. Interactions between gut microbiota and host metabolism predisposing to obesity and diabetes. Annu Rev Med. 2011;62:361-80.

68 Hamasaki H. Daily physical activity and type 2 diabetes: a review. World J Diabetes. 2016 Jun 25;7(12):243-51.

69 Colberg SR, Sigal RJ, Yardley JE, Riddell MC, Dunstan DW, Dempsey PC, et al. Physical activity/exercise and diabetes: a position statement of the American Diabetes Association. Diabetes Care. 2016 Nov;39(11):2065-79.

70 Snowling NJ, Hopkins WG. Effects of different modes of exercise training on glucose control and risk factors for complications in type 2 diabetic patients: a meta-analysis. Diabetes Care. 2006 Nov;29(11):2518-27.

71 Garber CE, Blissmer B, Deschenes MR, Franklin BA, Lamonte MJ, Lee IM, et al. American College of Sports Medicine position stand. Quantity and quality of exercise for developing and maintaining cardiorespiratory, musculoskeletal, and neuromotor fitness in apparently healthy adults: guidance for prescribing exercise. Med Sci Sports Exerc. 2011 Jul;43(7):1334-59.

72 Panagiotakos DB, Tzima N, Pitsavos C, Chrysohoou C, Papakonstantinou E, Zampelas A, et al. The relationship between dietary habits, blood glucose and insulin levels among people without cardiovascular disease and type 2 diabetes; the ATTICA study. Rev Diabet Stud. 2005 Winter;2(4):208-15.

73 Villegas R, Shu XO, Gao YT, Yang G, Elasy T, $\mathrm{Li} \mathrm{H}$, et al. Vegetable but not fruit consumption reduces the risk of type 2 diabetes in Chinese women. J Nutr. 2008 Mar;138(3):574-80.

74 Abdali D, Samson SE, Grover AK. How effective are antioxidant supplements in obesity and diabetes? Med Princ Pract. 2015;24(3): 201-15.

75 Asif $\mathrm{M}$. The prevention and control the type2 diabetes by changing lifestyle and dietary pattern. J Educ Health Promot. 2014;3:1.

76 Barnard RJ, Jung T, Inkeles SB. Diet and exercise in the treatment of NIDDM. The need for early emphasis. Diabetes Care. 1994 Dec; 17(12):1469-72.
77 Nicholson AS, Sklar M, Barnard ND, Gore S, Sullivan R, Browning S. Toward improved management of NIDDM: a randomized, controlled, pilot intervention using a lowfat, vegetarian diet. Prev Med. 1999;29(2):87-91.

78 Lacey K, Pritchett E. Nutrition care process and model: ADA adopts road map to quality care and outcomes management. J Am Diet Assoc. 2003 Aug;103(8):1061-72.

79 Franz MJ, MacLeod J. Success of nutritiontherapy interventions in persons with type 2 diabetes: challenges and future directions. Diabetes Metab Syndr Obes. 2018;11:265-70.

80 Cho Y-Y, Lee M-K, Jang H-C, Rha M-Y, Kim J-Y, Park Y-M, et al. The clinical and cost effectiveness of medical nutrition therapy for patients with type 2 diabetes mellitus. J Nutr Health. 2008;41(2):147-55.

81 Vasanth R, Ganesh A, Shanker R. Impact of stress on type 2 diabetes mellitus management. Psychiatr Danub. 2017 Sep;29(Suppl 3): 416-21.

82 Harris ML, Oldmeadow C, Hure A, Luu J, Loxton D, Attia J. Stress increases the risk of type 2 diabetes onset in women: a 12 -year longitudinal study using causal modelling. PLoS One. 2017;12(2):e0172126.

83 Kelly SJ, Ismail M. Stress and type 2 diabetes: a review of how stress contributes to the development of type 2 diabetes. Annu Rev Public Health. 2015 Mar 18;36:441-62.

84 Steptoe A, Hackett RA, Lazzarino AI, Bostock S, La Marca R, Carvalho LA, et al. Disruption of multisystem responses to stress in type 2 diabetes: investigating the dynamics of allostatic load. Proc Natl Acad Sci U S A. 2014 Nov 4;111(44):15693-8.

85 Hackett RA, Steptoe A. Type 2 diabetes mellitus and psychological stress: a modifiable risk factor. Nat Rev Endocrinol. 2017 Sep; 13(9):547-60.

86 Faulenbach M, Uthoff $\mathrm{H}$, Schwegler K, Spinas GA, Schmid C, Wiesli P. Effect of psychological stress on glucose control in patients with type 2 diabetes. Diabet Med. 2012 Jan;29(1): $128-31$

87 Arora T, Taheri S. Sleep optimization and diabetes control: a review of the literature. Diabetes Ther. 2015 Dec;6(4):425-68.

88 Vgontzas AN, Liao D, Pejovic S, Calhoun S, Karataraki M, Bixler EO. Insomnia with objective short sleep duration is associated with type 2 diabetes: a population-based study. Diabetes Care. 2009 Nov;32(11):1980-5.

89 Arora T, Taheri S. Sleep optimization and diabetes control: a review of the literature. Diabetes Ther. 2015 Dec;6(4):425-68.

90 De Bacquer D, Van Risseghem M, Clays E, Kittel F, De Backer G, Braeckman L. Rotating shift work and the metabolic syndrome: a prospective study. Int J Epidemiol. 2009 Jun; 38(3):848-54.

91 Xu Q, Song Y, Hollenbeck A, Blair A, Schatzkin $A$, Chen H. Day napping and short night sleeping are associated with higher risk of diabetes in older adults. Diabetes Care. 2010 Jan; $33(1): 78-83$. 
92 Buxton OM, Cain SW, O'Connor SP, Porter JH, Duffy JF, Wang W, et al. Adverse metabolic consequences in humans of prolonged sleep restriction combined with circadian disruption. Sci Transl Med. 2012 Apr 11; 4(129):129ra43.

93 Taheri S, Lin L, Austin D, Young T, Mignot E. Short sleep duration is associated with reduced leptin, elevated ghrelin, and increased body mass index. PLoS Med. 2004 Dec;1(3): e62.

94 Spiegel K, Leproult R, Van Cauter E. Impact of sleep debt on metabolic and endocrine function. Lancet. 1999 Oct 23;354(9188): 1435-9.

95 Dallmann R, Okyar A, Lévi F. Dosing-time makes the poison: circadian regulation and pharmacotherapy. Trends Mol Med. 2016; 22(5):430-45.

96 Fonseca VA. Defining and characterizing the progression of type 2 diabetes. Diabetes Care. 2009;32(Suppl 2):S151-6.

97 Sinha MK, Ohannesian JP, Heiman ML, Kriauciunas A, Stephens TW, Magosin S, et al. Nocturnal rise of leptin in lean, obese, and non-insulin-dependent diabetes mellitus subjects. J Clin Invest. 1996;97(5):1344.

98 Miyazaki M, Fujii T, Takeda N, Magotani H, Iwanaga K, Kakemi M. Chronopharmacological assessment identified GLUT4 as a factor responsible for the circadian variation of the hypoglycemic effect of tolbutamide in rats. Drug Metab Pharmacokinet. 2011; 26(5):503-15.

99 Schoeller DA, Cella LK, Sinha MK, Caro JF. Entrainment of the diurnal rhythm of plasma leptin to meal timing. J Clin Invest. 1997; 100(7):1882

100 Klok MD, Jakobsdottir S, Drent ML. The role of leptin and ghrelin in the regulation of food intake and body weight in humans: a review. Obes Rev. 2007;8(1):21-34.

101 Franks PW, Pearson E, Florez JC. Gene-environment and gene-treatment interactions in type 2 diabetes: progress, pitfalls, and prospects. Diabetes Care. 2013;36(5):141321.

102 Reinehr T, Friedel S, Mueller TD, Toschke AM, Hebebrand J, Hinney A. Evidence for an influence of TCF7L2 polymorphism rs7903146 on insulin resistance and sensitivity indices in overweight children and adolescents during a lifestyle intervention. Int J Obes. 2008 Oct;32(10):1521-4.

103 Cornelis MC, Hu FB. Gene-environment interactions in the development of type 2 diabetes: recent progress and continuing challenges. Annu Rev Nutr. 2012;32:245-59.

104 Kilpeläinen TO, Qi L, Brage S, Sharp SJ, Sonestedt E, Demerath E, et al. Physical activity attenuates the influence of FTO variants on obesity risk: a meta-analysis of 218,166 adults and 19,268 children. PLoS Med. 2011 Nov;8(11):e1001116.

105 Nettleton JA, McKeown NM, Kanoni S, Lemaitre RN, Hivert MF, Ngwa J, et al. Interactions of dietary whole-grain intake with fast- ing glucose- and insulin-related genetic loci in individuals of European descent: a metaanalysis of 14 cohort studies. Diabetes Care. 2010 Dec;33(12):2684-91.

106 Kido Y. Gene-environment interaction in type 2 diabetes. Diabetol Int. 2016;8(1):7-13.

107 Eid HM, Wright ML, Anil Kumar NV, Qawasmeh A, Hassan STS, Mocan A, et al. Significance of microbiota in obesity and metabolic diseases and the modulatory potential by medicinal plant and food ingredients. Front Pharmacol. 2017;8:387-7.

108 Cani PD, Amar J, Iglesias MA, Poggi M, Knauf C, Bastelica D, et al. Metabolic endotoxemia initiates obesity and insulin resistance. Diabetes. 2007 Jul;56(7):1761-72.

109 Chakraborti CK. New-found link between microbiota and obesity. World J Gastrointest Pathophysiol. 2015;6(4):110-9.

110 Liu Y, Lou X. Type 2 diabetes mellitus-related environmental factors and the gut microbiota: emerging evidence and challenges. Clinics. 2020;75:e1277.

111 Kumar H, Lund R, Laiho A, Lundelin K, Ley RE, Isolauri E, et al. Gut microbiota as an epigenetic regulator: pilot study based on whole-genome methylation analysis. mBio. 2014 Dec 16;5(6):e02113-14

112 Remely M, Aumueller E, Merold C, Dworzak S, Hippe B, Zanner J, et al. Effects of short chain fatty acid producing bacteria on epigenetic regulation of FFAR3 in type 2 diabetes and obesity. Gene. 2014 Mar 1;537(1): 85-92.

113 Gurung M, Li Z, You H, Rodrigues R, Jump DB, Morgun A, et al. Role of gut microbiota in type 2 diabetes pathophysiology. EBioMedicine. 2020 Jan;51:102590.

114 Yoshida N, Emoto T, Yamashita T, Watanabe $\mathrm{H}$, Hayashi T, Tabata T, et al. Bacteroides vulgatus and bacteroides dorei reduce gut microbial lipopolysaccharide production and inhibit atherosclerosis. Circulation. 2018 Nov 27;138(22):2486-98.

115 Kang JH, Yun SI, Park MH, Park JH, Jeong SY, Park HO. Anti-obesity effect of Lactobacillus gasseri BNR17 in high-sucrose dietinduced obese mice. PLoS One. 2013;8(1): e54617.

116 Zhang Y, Guo X, Guo J, He Q, Li H, Song Y, et al. Lactobacillus casei reduces susceptibility to type 2 diabetes via microbiota-mediated body chloride ion influx. Sci Rep. 2014 Jul 18;4(1):5654.

117 Rodríguez-Gutiérrez R, Montes-Villarreal J, Rodríguez-Velver KV, González-Velázquez C, Salcido-Montenegro A, Elizondo-Plazas A, et al. Metformin use and vitamin B12 deficiency: untangling the association. Am J Med Sci. 2017 Aug;354(2):165-71.

118 Association AD. 9. Pharmacologic approaches to glycemic treatment: standards of medical care in diabetes 2019. Diabetes Care. 2019;42(Suppl 1):S90-S102.

119 Nasri H, Rafieian-Kopaei M. Metformin: current knowledge. J Res Med Sci. 2014; 19(7):658-64.
120 Kalra S, Kesavadev J, Chadha M, Kumar GV Sodium-glucose cotransporter-2 inhibitors in combination with other glucose-lowering agents for the treatment of type 2 diabetes mellitus. Indian J Endocrinol Metab. 2018 Nov-Dec;22(6):827-36.

121 Hsia DS, Grove O, Cefalu WT. An update on sodium-glucose co-transporter-2 inhibitors for the treatment of diabetes mellitus. Curr Opin Endocrinol Diabetes Obes. 2017 Feb; 24(1):73-9.

122 Peters AL, Buschur EO, Buse JB, Cohan P, Diner JC, Hirsch IB. Euglycemic diabetic ketoacidosis: a potential complication of treatment with sodium-glucose cotransporter 2 inhibition. Diabetes Care. 2015 Sep;38(9):1687-93.

123 Chowdhary M, Kabbani AA, Chhabra A. Canagliflozin-induced pancreatitis: a rare side effect of a new drug. Ther Clin Risk Manag. 2015;11:991-4.

124 Srivali N, Thongprayoon C, Cheungpasitporn W, Ungprasert P. Acute pancreatitis in the use of canagliflozin: a rare side-effect of the novel therapy for type 2 diabetes mellitus. J Basic Clin Pharm. 2015 Jun;6(3):101-2.

125 Filippatos TD, Panagiotopoulou TV, Elisaf MS. Adverse effects of GLP-1 receptor agonists. Rev Diabet Stud. 2014 Fall-Winter; 11(3-4):202-30.

126 Nakata H, Sugitani S, Yamaji S, Otsu S, Higashi Y, Ohtomo Y, et al. Pancreatitis with pancreatic tail swelling associated with incretin-based therapies detected radiologically in two cases of diabetic patients with end-stage renal disease. Intern Med. 2012; 51(21):3045-9.

127 Ayoub WA, Kumar AA, Naguib HS, Taylor HC. Exenatide-induced acute pancreatitis. Endocr Pract. 2010 Jan-Feb;16(1):80-3.

128 Lee PH, Stockton MD, Franks AS. Acute pancreatitis associated with liraglutide. Ann Pharmacother. 2011 Apr;45(4):e22.

129 Butler PC, Elashoff M, Elashoff R, Gale EA A critical analysis of the clinical use of incretin-based therapies: are the GLP-1 therapies safe? Diabetes Care. 2013 Jul;36(7):2118-25.

130 Elashoff M, Matveyenko AV, Gier B, Elashoff R, Butler PC. Pancreatitis, pancreatic, and thyroid cancer with glucagon-like peptide-1-based therapies. Gastroenterology. 2011;141(1):150-6.

131 Feng X, Cai A, Dong K, Chaing W, Feng M, Bhutada NS, et al. Assessing pancreatic cancer risk associated with dipeptidyl peptidase 4 inhibitors: data mining of FDA Adverse Event Reporting System (FAERS). J Pharmacovigilance. 2013:1-7.

132 Su B, Sheng H, Zhang M, Bu L, Yang P, Li L, et al. Risk of bone fractures associated with glucagon-like peptide-1 receptor agonists' treatment: a meta-analysis of randomized controlled trials. Endocrine. 2015 Feb;48(1) $107-15$.

133 Zhang DW, Fu M, Gao SH, Liu JL. Curcumin and diabetes: a systematic review. Evid Based Complement Alternat Med. 2013; 2013:636053. 
134 Ghorbani A. Mechanisms of antidiabetic effects of flavonoid rutin. Biomed Pharmacother. 2017;96:305-12.

135 Li R, Zhang Y, Rasool S, Geetha T, Babu JR. Effects and underlying mechanisms of bioactive compounds on type 2 diabetes mellitus and Alzheimer's disease. Oxid Med Cell Longev. 2019;2019:8165707.

136 Youl E, Bardy G, Magous R, Cros G, Sejalon F, Virsolvy A, et al. Quercetin potentiates insulin secretion and protects INS-1 pancreatic $\beta$-cells against oxidative damage via the
ERK1/2 pathway. Br J Pharmacol. 2010; 161(4):799-814.

137 Park SA, Choi M-S, Cho S-Y, Seo J-S, Jung UJ, Kim M-J, et al. Genistein and daidzein modulate hepatic glucose and lipid regulating enzyme activities in $\mathrm{C} 57 \mathrm{BL} / \mathrm{KsJ}-\mathrm{db} / \mathrm{db}$ mice. Life Sci. 2006;79(12):1207-13.

138 Mahmoud AM, Ashour MB, Abdel-Moneim A, Ahmed OM. Hesperidin and naringin attenuate hyperglycemia-mediated oxidative stress and proinflammatory cytokine production in high fat fed/streptozotocin- induced type 2 diabetic rats. J Diabetes Complicat. 2012;26(6):483-90.

139 Singh AK, Raj V, Keshari AK, Rai A, Kumar $\mathrm{P}$, Rawat $\mathrm{A}$, et al. Isolated mangiferin and naringenin exert antidiabetic effect via PPAR. Chem Biol Interact. 2018;280:33-44.

140 Prasath GS, Pillai SI, Subramanian SP. Fisetin improves glucose homeostasis through the inhibition of gluconeogenic enzymes in hepatic tissues of streptozotocin induced diabetic rats. Eur J Pharmacol. 2014;740:24854. 